\title{
Evaluation of the Significance of Obtaining Two Histopathological Samples from the Same Kidney at Autopsy Examination
}

\author{
Sanjeewa $\mathrm{HKR}^{1^{*}}$, Vidanapathirana $\mathrm{M}^{2}$, Attygalle $\mathrm{U}^{1}$, Amararatne RRGS ${ }^{3}$, Senasinghe DPP \\ ${ }^{1}$ Office of the Judicial Medical Officer, Base hospital Panadura, Sri Lanka \\ ${ }^{2}$ Department of Forensic Medicine, Faculty of Medical Sciences, University of Sri Jayewardenepura, Sri Lanka \\ ${ }^{3}$ Office of the Judicial Medical Officer, General Hospital Kalutara, Sri Lanka \\ ${ }^{4}$ Office of the Judicial Medical Officer, General Hospital Kegalle, Sri Lanka
}

\begin{abstract}
Introduction: Histopathology examination is a common and recommended practice among all types of autopsy practitioners; there are few scientific outlooks guidelines or protocols about the number of samples that need to be obtained at autopsy for the histopathology examination. The aim of this study was to evaluate the value of taking multiple samples from the same kidney at autopsy examination.

Methodology: A cross-sectional descriptive prospective study was carried out among 108 post mortem reports and histopathology samples at the department of forensic medicine of Base Hospital Panadura and District General Hospital Kalutara and Kegalle. All autopsies with available microscopic samples of kidney irrespective of the cause of death were used for the study. The data collection process was carried out from November 2019 to February 2020 and the ethical clearance was obtained prior to the data collection.

Results: Data from the 108 post mortem reports were obtained. The studied sample consists of $69 \%(\mathrm{n}=74)$ of males and $31 \%(n=34)$ females. With regard to the age distribution, the majority of $40 \%(n=43)$ cases belonged to the $51-70$ age category. $69 \%(n=74)$ samples were collected from the left kidney while remaining $31 \%(n=34)$ from the right. Considering the macroscopic appearance of the kidney, cortical thickness reduction was noted among $34 \%(n=37)$ samples followed by granular contracted kidney of $31 \%(n=33)$. In the microscopic findings, the different numbers of pathologies were identified in both samples. However, the 1st sample had a higher frequency of histopathological findings than sample 2 and no significant difference in identification pathologies between 1 st sample and 2 nd samples were determined $(\mathrm{p}=0.784>0.05$.)
\end{abstract}

Conclusion: Taking two samples from same kidney during the autopsy does not suggest statistical difference. However, where the resources are available it is suggested that taking two samples is beneficial.

Keywords: Multiple kidney samples, autopsy findings, histopathological evaluation

Received: 02 April 2020, Revised version accepted: 29 June 2020, Published: 30 June 2020. *Corresponding author: Sanjeewa HKR, $\triangle$ Email: sanjweewa2307@yahoo.com, (D) ORCID https://orcid.org/0000-0001-8895-739X

Cite this article as: Sanjeewa HKR, Vidanapathirana M , Attygalle U , Amararatne RRGS , Senasinghe DPP. Evaluation of the Significance of Obtaining Two Histopathological Samples from the Same Kidney at Autopsy Examination. Medico-Legal Journal of Sri Lanka. 2020;8(1):15-18. DOI: http://doi.org/10.4038/mljsl.v8i1.7404

Copyright: @ 2019 with the Medico-legal Journal of Sri Lanka.

This is an open-access article distributed under the terms of the Creative Commons Attribution 4.0 International License, which permits unrestricted use, distribution and reproduction in any medium provided the original author and source are credited.

\section{Introduction}

An autopsy is a scientific examination that is systematically conducted and includes collecting samples for the purpose of additional testing by carefully dissecting and observing the body and organs. The specific examination goals depend on the nature of the case. Human autopsies often generate both legal and medical information. The histopathology plays a major contribution in diagnosis, in autopsy practice among other examination methods. However it is not a simple procedure. It needs some practice and also depends on a number of factors such as sample number, section type, stain type, frequency, etc. The systematically well-conducted histopathological and anatomical evaluation will provide the cause of death in autopsy examination in scientific manner. ${ }^{[1]}$

The number of samples to be collected for the histopathology during autopsy is highly subjective. It affects the final outcome in several ways. Because, inappropriate number of samples is 
associated with poor representation of pathology, missing of some specific features of the pathology. Adequate numbers of sample/multiple samples are associated with the proper presentation of the pathology.

There are few scientific outlooks guidelines or protocols about the number of samples that need to be obtained at autopsy for the histopathology examination.

Nevertheless, during the post mortem, two or more samples are taken from all the solid organs except kidney by most of the judicial medical officers. But, Royal Stoke University Hospital in United Kingdom practices obtaining two or more samples from the kidney as well. ${ }^{[2]}$

Autopsy kidneys show clinical as well as medical lesions. In which we can come to the exact cause of death and can comment about clinic- pathological correlation including the clinical features, the investigation reports and post mortem gross and microscopic findings ${ }^{[3,4,5]}$ Certain renal pathologies might not affect the renal function thereby not causing clinical manifestations. Therefore obtaining multiple samples is very important for the identification of undiagnosed pathology. Because a single sample does not always represent all the pathology, eg - in Pyelonephritis, some parts of the kidney are nearly normal in histopathology studies as a result, it will lead to wrong conclusion. ${ }^{[5]}$

Obtaining histopathology samples are done routinely during an autopsy examination. The number of samples obtained is a subjective phenomenon and it varies from pathologist to pathologist and institute to institute. It may lead to a waste of resources, money and manpower.

The study was done to evaluate the necessity of obtaining two or more samples from the same kidney at autopsy. The research provides some knowledge on the pros and cons of taking two samples from the same kidney at autopsy.

\section{Methods}

The study was conducted as cross-sectional descriptive retrospective study. Sample collection from the post mortems was carried out parallel at the departments of forensic medicine of Base Hospital Panadura and District General Hospital Kalutara and Kegalle from November 2018 to November 2019.

All autopsies with available microscopic samples of kidney irrespective of the cause of death are included for the study further post mortem reports where no descriptions regarding the gross pathology/findings of the kidney were excluded. Every other post mortems were selected for the study after considering the inclusion and exclusion criteria.

Ethical clearance was obtained from the National Institute of Health Sciences, Nagoda, Kalutara Sri Lanka. Permission from the relevant hospital authority was also obtained to proceed with the study. Permission to attain relevant data and two or more sample reports were obtained from the respective coroner/s,

\section{Results}

A sample of 108 post mortem reports and histopathology samples were obtained from three centers at the same time.

Table. 01: Demographic Information

\begin{tabular}{llr}
\hline Characteristics & $\begin{array}{r}\mathbf{N = 1 0 8} \\
\mathbf{n}(\boldsymbol{\%})\end{array}$ \\
\hline Age & $<30$ years & $05(05)$ \\
& $30-50$ years & $36(33)$ \\
& $51-70$ years & $43(40)$ \\
& $>70$ years & $24(22)$ \\
Gender & Male & $74(69)$ \\
& Female & $34(31)$ \\
\hline
\end{tabular}

Considering the demographic factors of the sample, the majority of $40 \%(n=43)$ belongs to the age group between 50-70 whereas the lowest recorded among age category below 30 years of $5 \%(n=5)$. The male representation noted considerably high which represented $69 \%(n=74)$ out of total furthermore the highest female representation accumulated from the age group above 70 while highest male representation gained from the age group between 51-70 category.

As far as the medical history of the sample concerns, hypertension claimed as highest prevalence among the studied population with $48 \% \quad(n=37)$ and diabetes mellitus and ischemic heart disease equally noted among $24 \%(\mathrm{n}=19)$ cases.

Table 02: Duration of Illness and Duration of Treatment

\begin{tabular}{llr}
\hline Duration & $\begin{array}{r}\mathbf{( N = 1 0 8 )} \\
\mathbf{n}(\%)\end{array}$ \\
\hline Illness & $\leq 1$ year & $03(04)$ \\
& $1-5$ years & $23(34)$ \\
& 5 -10 years & $22(31)$ \\
& $\geq 10$ years & $22(31)$ \\
Treatment & $\leq 1$ year & $02(03)$ \\
& 1 - 5 years & $24(36)$ \\
& $5-10$ years & $20(30)$ \\
& $\geq 10$ years & $21(31)$ \\
\hline
\end{tabular}


The duration of the illness and duration of treatment years noted in the cases in which $\leq 1$ year illness duration $04 \%(n=03)$ and $2(3 \%)$ from the total sample start treatment under 1 year time, moreover from cases which duration of the illness running more than 10 years' time $31 \%(n=22)$ followed the treatment regime parallelly until the demise $31 \%$ $(n=21)$.

Table 03: Cause of Death

\begin{tabular}{lr}
\hline Cause & $\begin{array}{r}(\mathbf{N}=\mathbf{1 0 8}) \\
\mathbf{n}(\%)\end{array}$ \\
\hline Sepsis & $12(11)$ \\
Heart disease & $33(31)$ \\
Respiratory disease & $22(20)$ \\
Internal Haemorrhage & $16(15)$ \\
Other & $25(23)$
\end{tabular}

The majority of $31 \% \quad(n=33)$ from the sample populations' deaths were caused by heart-related disease followed by $20 \%(\mathrm{n}=22)$ respiratory-related disease and $23 \%(n=25)$ other different cases.

With regard to the sample collection, $68 \%(n=74)$ samples were collected from the left kidney while remaining $32 \%(n=34)$ samples were collected from the right kidney of the studied.

Table 04: Macroscopic examination findings of kidney

\begin{tabular}{lr}
\hline $\begin{array}{l}\text { Macroscopic appearance of the } \\
\text { kidney }\end{array}$ & $\begin{array}{r}(\mathbf{N}=\mathbf{1 0 8}) \\
\mathbf{n}(\boldsymbol{\%})\end{array}$ \\
\hline Granular contracted kidney & $33(31)$ \\
Congested Medulla & $27(25)$ \\
Cortical thickness reduced & $37(35)$ \\
Cortical scarring & $09(08)$ \\
Pale kidney & $25(23)$ \\
Unremarkable & $19(18)$ \\
\hline
\end{tabular}

Considering the macroscopic appearance of the kidney, cortical thickness reduction was noted among $34 \%(n=37)$ samples followed by granular contracted kidney of $30 \%(n=33)$ and congested medulla of $25 \%(n=27)$ from the total study sample.

Table 05: Microscopic finding of the samples

\begin{tabular}{lrr}
\hline $\begin{array}{l}\text { Pathology } \\
\text { category }\end{array}$ & $\begin{array}{r}\text { 1st sample } \\
(\mathbf{N}=\mathbf{1 0 8}) \\
\mathbf{n}(\mathbf{\%})\end{array}$ & $\begin{array}{r}\text { 2nd sample } \\
(\mathbf{N = 1 0 8}) \\
\mathbf{n}(\boldsymbol{\%})\end{array}$ \\
\hline Glomerular change & $77(71)$ & $75(69)$ \\
Vascular change & $95(90)$ & $87(81)$ \\
Tubular change & $22(20)$ & $22(20)$ \\
Interstitial change & $23(21)$ & $17(16)$ \\
\hline
\end{tabular}

Upon microscopic findings, the different numbers of pathologies were identified in both samples. However, the 1st sample had a higher frequency of histological findings than sample 2.
Table 06: Comparison of mean score according to histology sample

\begin{tabular}{lllr}
\hline $\begin{array}{l}\text { Pathology } \\
\text { category }\end{array}$ & $\begin{array}{l}\text { Histology } \\
\text { sample 1 }\end{array}$ & $\begin{array}{l}\text { Histology } \\
\text { sample 2 }\end{array}$ & $\begin{array}{r}\text { P } \\
\text { value }\end{array}$ \\
\hline Mean Score & $2.50 \pm 1.072$ & $2.59 \pm 0.816$ & 0.786 \\
\hline
\end{tabular}

With the calculated mean score of the predefined scoring system, the total mean was 2.50 in sample 1 and 2.59 in sample 2. Hence the data was skewed, non-parametric was used to assess the significance. Mann Whitney U test was carried out and the pvalue was $0.786(p>0.05)$. Hence was no significant difference in identification pathologies between one sample and two samples were determined.

\section{Discussion}

During the 1960s, around a third of death certificates were incorrect. Also, around 50\% of the autopsy had findings in the patients said to be unsuspected deaths. However, about $20 \%$ of clinically unexpected findings which include $5 \%$ of major findings also were found during the examination of the histopathological findings. ${ }^{6]}$

Researcher has examined the patients aged from the $30 \mathrm{~s}$ to above $70 \mathrm{~s}$ mostly where males and predominant and highest frequent comorbidity identified as hypertension which was there among $47 \%$ patients. The highest frequency of cause of death noted as heart disease-related deaths (31\%). Hypertension might act as a risk factor on development of atherosclerosis and may lead to heart disease related death.

At present, multiple samples are taken during the postmortem examination for histopathological assessment. This protocol is carried out to ensure the identification of underlying histopathological findings of all the tissues examined. One might argue that macroscopic examination would easy to recognize the underlying pathologies rather than sampling. Nonetheless, there might be discrepancies in the macroscopic and microscopic findings of tissue pathologies. In practice, multiple histological samples are obtained from brain, heart, lungs, liver and spleen in order to minimize the missing a localized pathology. But it is observed that a single sample is taken from the kidney for histological assessment which might miss a localized pathology in a kidney. Local micro infarctions, small abscess or glomerular pathologies may easily be missed even by an experienced Judicial Medical Officer.

As far as macroscopic appearance is concerned, the highest number of patients had reduced cortical thickness in their kidneys $(35 \%, \mathrm{n}=37)$. Granular contracted kidneys were detected in $31 \% \quad(n=33)$ individuals. However, glomerular changes were detected around 100 patients in both 
histopathological samples which might not reflect the frequencies of reduced cortical thickness.

In the present study the main objective was to evaluate the reliability of the assessment of a single histopathology sample. Researcher has obtained two samples from the different aspects of the same kidney and evaluates them histopathologically. The histopathological findings were categorized into 4 main domains. They are glomerular changes, vascular changes, tubular changes and interstitial changes. According to the presence of each domain each sample was scored and those scores were compared between 2 samples. The histological evaluation and scoring were done by the most experienced Judicial Medical Officer in the unit.

When comparing each domain it has been observed that the 1st sample had detected a higher number of pathologies than the 2nd sample. However the observation is not statistically significant ( $\mathrm{p}=0.786>0.05)$ according to the Mann Whitney $U$ test. Due to the limited resources and facilities, we would suggest obtaining a single sample from the kidney as it would not make such a significant difference.

\section{Conclusion}

Taking two samples from same kidney during the autopsy do not suggest statistical difference. However, where the resources are available it is suggested that taking two samples is beneficial.

\section{Acknowledgements}

Perera KKS, Fawaz AM Medical officers, Office of the Judicial Medical Officer, Base Hospital Panadura for assisting in collection of data.

\section{References}

1. Russell SS. "Autopsies". In Ayn Embar-seddon, Allan D. Pass (eds.). Forensic Science. Salem Press. 2008. p. 95. ISBN 978-1-58765-423-7.

2. Penner DW. Cost-effectiveness of the autopsy in maintaining and improving the standard of patient care. Am J Clin Pathol. 1978 Feb;69(2 Suppl):250-2.

3. Kauret A, Bodal VK, Garg $\mathrm{P}$ et al: Histopathological Spectrum of Kidney lesions in autopsy-A study of 100 case. JMSCR. 2018;06 (02): 962-6

4. Byard RW, Winskog C. Histology in forensic practice: required or redundant? Forensic Sci Med Pathol 2012:8(1):56-7.

5. Patel S, Rajalakshmi BR, Manjunath GV. Histopathologic Findings in Autopsies with emphasis on interesting and incidental findings-A Pathologist's Perspective. J Clin Diagn Res. 2016 Nov;10(11): EC 08-12.
6. Roulson JA, Benbow EW, Hasleton PS. Discrepancies between clinical and autopsy diagnosis and the value of post mortem histology; a meta - analysis and review. Histopathology. 2005 Dec;47(6):551-9. 